\title{
Study of Biofilm Formation \& Drug Resistance Pattern in Various Candida Species Isolated from Patients with Urinary Tract Infection
}

\author{
Padmaja Yarlagadda ", Uma Penmetcha, Naseema Shaik and Ramesh Babu Myneni \\ Department of Microbiology NRI Medical College and General Hospital, \\ Chinakakani - 522503 Andhra Pradesh, India \\ *Corresponding author
}

\section{Keywords}

Bio film, Candida spp, Urinary tract infection, Antifungal sensitivity tests.

Article Info

Accepted:

10 July 2017

Available Online:

10 September 2017

\section{A B S T R A C T}

Candidal lower urinary tract infection (UTI) is quite frequently seen in association with indwelling catheters, and may originate from the gastrointestinal or genitalbiota. The frequency of urinary tract infections (UTIs) due to Candida spp. is increasing and these infections are now being the most common clinical finding, particularly in hospitalized patients. It is common in the patients admitted in intensive care units, individuals with multiple predisposing factors, including diabetes mellitus, indwelling urine catheter, long term exposure to antibiotics and immunosuppressive therapy. Non albicans Candida species appear better adopted to the urinary tract environment and are more resistant to antifungal drugs compared to $C$. albicans. Early and prompt diagnosis, proper treatment and prevention of candiduria due to biofilms pose a major challenge for microbiologists and clinicians worldwide. The aim of the study was to detect biofilm producing ability of various Candida species isolated from Catheterized and Non-catheterized candiduria patients hospitalized in NRI General Hospital. A total of 100 Candida spp isolates from both Catheterized and Non-catheterized patients with candiduria were taken for the study. The Candida spp isolates were identified by using conventional methods, rapid identification by HICHROM agar and their ability to produce biofilm was detected by the tube method. Antifungal susceptibility testing of all Candida isolates was performed using the disk diffusion method. Statistical analysis was done by Statistical Package for the Social Sciences (SPSS) software version 20. A total of 100Candida spp were isolated from 37 catheterized and 63 Non-catheterized patients. Among them 84 were Non Albicans Candida (NAC).Biofilm was produced by $48(48 \%)$ isolates. Most of Biofilm producing Candida species were resistant to clotrimazole (26\%) and fluconazole (25\%). The present study suggests an increasing prevalence of Non Albicans Candida in urine samples and also shows them to be strong biofilm producers when compared to C. albicans. Biofilm formation also helps the organism to overcome host defenses and exists as a persistent source of infection. Biofilm production found to be of more significance to Non Albicans Candida than $C$. albicans. Thus more remains to be determined about biofilms formed by the Non Albicans Candidaas they are now, frequently encountered isolates in candidurias.

\section{Introduction}

Candidasp pcan be either commensals or opportunistic pathogens. Pathogenic fungi in the genus Candida are capable of causing a variety of infections ranging from superficial to deep-seated mycoses. The Candida spp have been recognized as the fourth 
commonest cause of nosocomial invasive infections. ${ }^{1}$ Candida organisms are commensals; and to act as pathogens, interruption of normal host defences is necessary. Therefore, general risk factors for Candida infections include immunecompromised states, diabetes mellitus, and iatrogenic factors like antibiotic use, indwelling devices, intravenous drug use, and hyperalimentation fluids.

Most pathogens, including Candida species have developed an effective battery of putative virulence factors and specific strategies to assist in colonization, invasion, and pathogenesis. The virulence factors expressed by Candida species, to cause infections may vary depending on the type of infection, the site and stage of infection, and the nature of the host response. ${ }^{2}$

The importance of epidemiological monitoring of yeasts involved in pathogenic processes is unquestionable due to the increase of these infections over the last decade, so are the changes observed in species causing candidiasis and empirical antifungal treatment. ${ }^{3}$

One of the important factors contributing to the virulence of candida is the formation of surface-attached microbial communities known as "biofilm". ${ }^{4}$ Biofilms are defined as structured microbial communities that are attached to a surface and encased in a matrix of exopolymeric material. ${ }^{5}$ A typical laboratory fungal model of biofilm formation involves two operational steps: (a) adhesion and (b) biofilm growth and maturation and has 3 distinct developmental phases: early (0$11 \mathrm{~h})$, intermediate (12-30 h) and mature (38$72 \mathrm{~h}$ ). The detailed structure of mature C.albicans biofilms consists of a dense network of yeast, hyphae and pseudohyphae. ${ }^{6}$ The advantages of forming biofilm include protection from the environment, nutrient availability, metabolic cooperation and acquisition of new traits. ${ }^{2}$

Candidal lower urinary tract infection (UTI) is quite frequently seen in association with indwelling catheters, and may originate from the gastrointestinal or genital biota. The frequency of urinary tract infections (UTIs) due to Candida species is increasing and these infections are now being the most common clinical finding, particularly in hospitalized patients.

Although C. albicans is the organism most often associated with serious fungal infection, other Candida species also have emerged as clinically important opportunistic pathogens. Non albicans Candida species appear better adopted to the urinary tract environment and are more resistant to antifungal drugs compared to $C$. albicans. Early and prompt diagnosis, proper treatment and prevention of candiduria due to biofilms pose a major challenge for microbiologists and clinicians worldwide.

The objectives of this study was identification and detection of biofilm production in Candida species isolated from catheterized and Non-catheterized candiduria patients hospitalized in NRI general hospital and their antifungal susceptibility patterns.

\section{Materials and Methods}

A total of 100 Candida isolates from both catheterized and Non-catheterized patients with candiduria were taken for the study. The Candida isolates were identified by using conventional methods, Rapid identification by HICHROM agar and their ability to produce biofilm was detected by the tube method.

The candida isolates obtained were further identified by methods such as germ tube test, microscopic morphology on cornmeal agar 
(Figure 1) and sugar fermentation and assimilation tests (Figure 2). ${ }^{7}$ Culture on CHROM agar (Figure 3) was also used for identification of the species.

Biofilm formation was determined for all the isolates and the standard strains by using a method proposed by Branchini et al., ${ }^{8} \mathrm{~A}$ loopful of organisms from the SDA plate was inoculated into a tube containing $10 \mathrm{ml}$ Sabouraud's liquid medium supplemented with glucose (final concentration of $8 \%$ ). The tubes were incubated at $37^{\circ} \mathrm{C}$ for $24 \mathrm{~h}$ after which the broth was aspirated out and the walls of the tubes were stained with safranin. Biofilm formation was scored as negative $(0+)$, weak positive $(1+)$, moderate positive $(2+)$, or strong positive (3+) (Figure 4).

Antifungal susceptibility testing of all Candida isolates was performed using the disk diffusion method. Statistical analysis was done by using Statistical Package for the Social Science (SPSS) software version 20.

\section{Results and Discussion}

A total of 100 Candida species were isolated from 37 catheterized and 63 Non-catheterized patients.
The Candida isolates identified by various methods are shown in table 1 . Among them 84 were Non Albicans Candida (NAC). Among the Non Albicans Candida, the most common isolate was C. tropicalis. Biofilm was produced by $48(48 \%)$ isolates. Among the Non Albicans Candida species, $C$. tropicalis was the highest biofilm producer and the other isolates was shown in table 2 . The intensity of biofilm production by the isolates was shown in table 3. Antifungal susceptibility testing of Candida spp was shown in table 4.

Most of Biofilmproducing Candida species were resistant to clotrimazole (11\%) and fluconazole (7\%).

Urinary Tract Infection (UTI) is the most common type of nosocomial infections and10 to $15 \%$ of UTIs are caused by Candidaspecies. ${ }^{9}$ the incidence of nosocomial candidiasis has increased dramatically over the last few decades. Their emergence as important nosocomial pathogens is related to specific risk factors associated with modern medical procedures, notably the use of immunosuppressive and cytotoxic drugs, powerful antibiotics, and implanted devices of various kinds. ${ }^{10}$

Fig.1 Chlamydospore formation on cornmeal agar

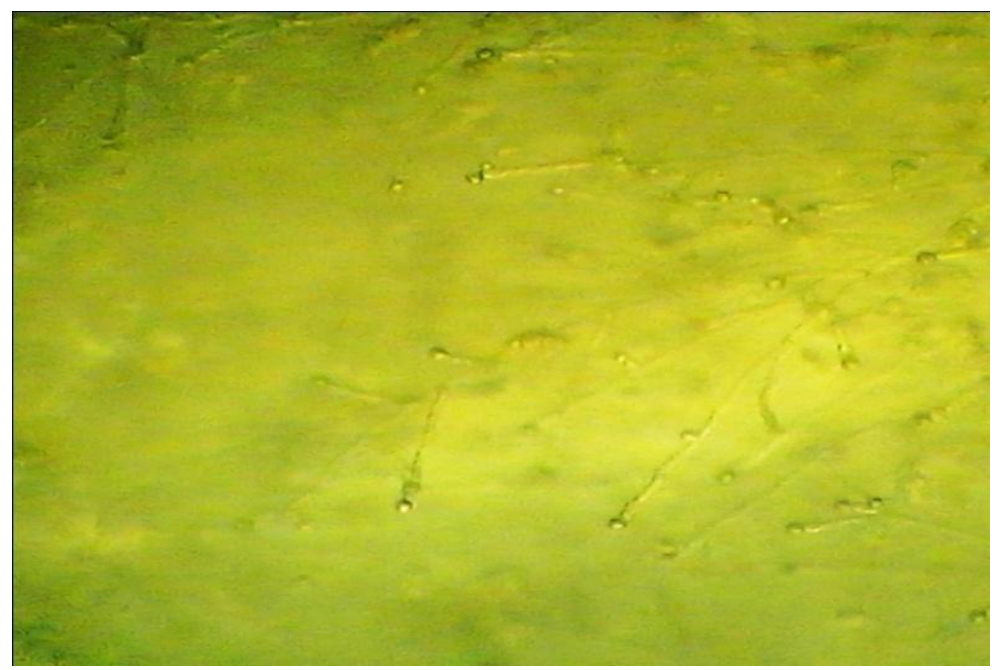


Fig.2 Sugar fermentation tests

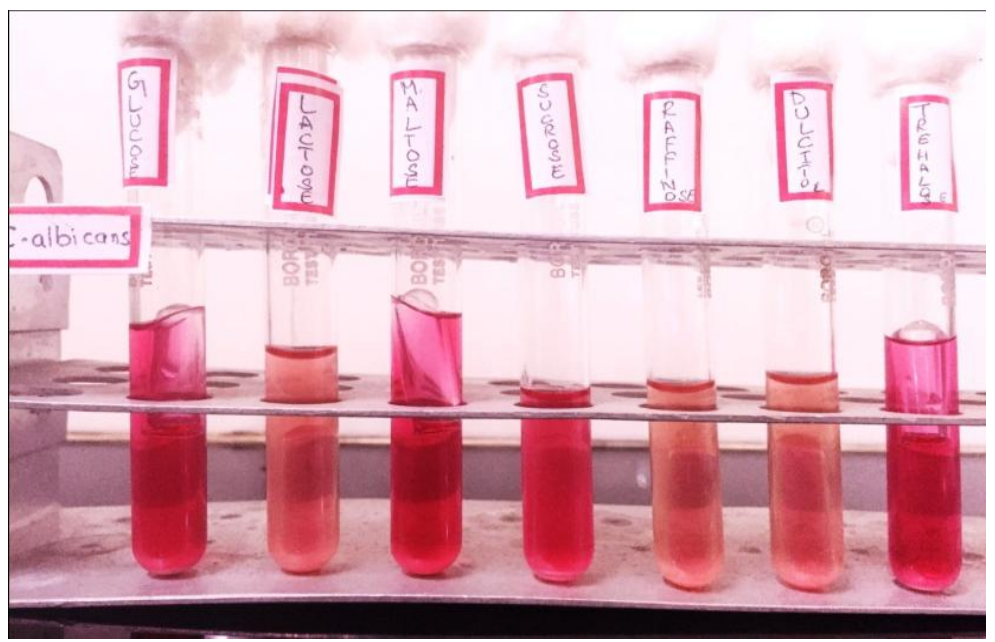

Figure.3 Growth on Hi Chrome Agar

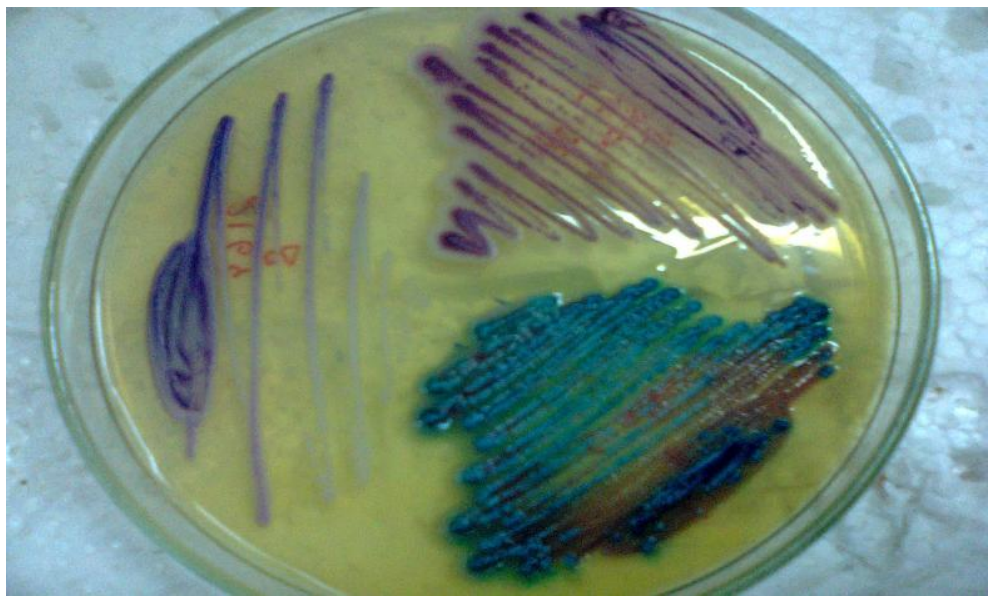

Fig.4 Intensity of Biofilm formation

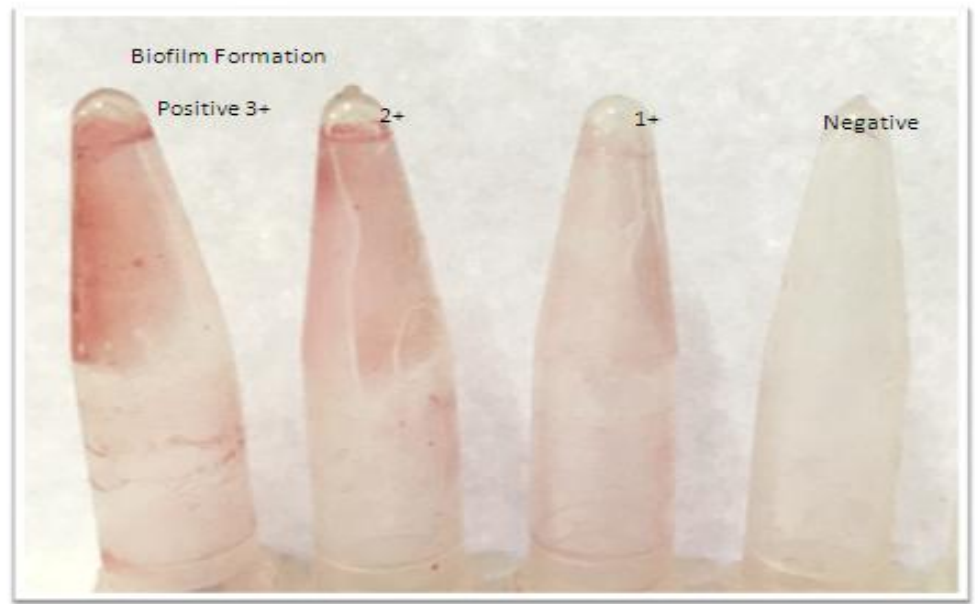


Table.1

\section{Various Candida spp isolated from UTI cases of Catheterized \& Non-Catheterized patients}

\begin{tabular}{|l|l|l|l|}
\hline $\begin{array}{l}\text { Candida Species } \\
\text { isolated }\end{array}$ & Catheterized (\%) & Non-catheterized (\%) & Total \\
\hline C. tropicalis & $24(33.8)$ & $47(66.1)$ & 71 \\
\hline C. albicans & $7(43.7)$ & $9(56.2)$ & 16 \\
\hline C. dubliniensis & $1(33.3)$ & $2(66.6)$ & 3 \\
\hline $\begin{array}{l}\text { C. famata } \\
\text { C. krusei }\end{array}$ & $1(33.3)$ & $2(66.6)$ & 3 \\
\hline C. kefyr & $2(66.6)$ & $1(33.3)$ & 3 \\
\hline C. guilliermondii & 0 & $2(100)$ & 2 \\
\hline Total & $2(100)$ & 0 & 2 \\
\hline chisquare & $37(37)$ & $63(63)$ & 100 \\
\hline P value & 1.09 & & \\
\hline
\end{tabular}

Table.2

Intensity of biofilm formation among various candida isolates

\begin{tabular}{|l|l|l|l|l|l|}
\hline $\begin{array}{l}\text { Candida Species } \\
\text { isolated }\end{array}$ & Positive(\%) & $3+$ & $2+$ & $1+$ & Negative(\%) \\
\hline C. tropicalis (71) & $36(50.7)$ & 9 & 17 & 10 & $35(49.2)$ \\
\hline C. albicans (16) & $4(25)$ & 1 & 2 & 1 & $12(75)$ \\
\hline C. dubliniensis (3) & $2(66.6)$ & 2 & 0 & 0 & $1(33.3)$ \\
\hline C. famata (3) & $1(33.3)$ & 1 & 0 & 0 & $2(66.6)$ \\
\hline C. krusei (3) & $2(66.6)$ & 0 & 0 & 2 & $1(33.3)$ \\
\hline C. kefyr (2) & $1(50)$ & 0 & 1 & 0 & $1(50)$ \\
\hline C. guilliermondii (2) & $2(100)$ & 0 & 2 & 0 & 0 \\
\hline Total & 48 & 13 & 22 & 13 & 52 \\
\hline Chi square & 4.55 & & P value & .102, ie; $>0.5$ & $\begin{array}{l}\text { Not } \\
\text { significant }\end{array}$ \\
\hline
\end{tabular}


Table.3

\section{Biofilm Formation in various Candida spp in UTI of catheterized \& Non-catheterized patients}

\begin{tabular}{|l|l|l|l|}
\hline $\begin{array}{l}\text { Candida Species } \\
\text { isolated }\end{array}$ & Positive & Catheterized & Non-catheterized \\
\hline C. tropicalis & $36(75)$ & $17(47.2)$ & $19(52.7)$ \\
\hline C. albicans & $4(8.3)$ & $4(100)$ & 0 \\
\hline C. dubliniensis & $2(4.1)$ & $2(100)$ & 0 \\
\hline C. famata & $1(2.0)$ & $1(100)$ & 0 \\
\hline C. krusei & $2(4.1)$ & $1(50)$ & $1(50)$ \\
\hline C. kefyr & $1(2.0)$ & $1(100)$ & 0 \\
\hline C. guilliermondii & $2(4.1)$ & 0 & $2(100)$ \\
\hline Total & 48 & $26(54.1)$ & $22(45.9)$ \\
\hline & & & \\
\hline
\end{tabular}

Table.4

Antifungal susceptibility pattern among Candida isolates

\begin{tabular}{|c|c|c|c|c|c|c|c|c|c|c|c|c|c|c|}
\hline \multirow{2}{*}{$\begin{array}{l}\text { CANDIDA } \\
\text { SPECIES } \\
\text { ISOLATED }\end{array}$} & \multicolumn{2}{|c|}{$\begin{array}{l}\text { AMPHOTERICIN } \\
\text { B }\end{array}$} & \multicolumn{2}{|c|}{ NYSTATIN } & \multicolumn{2}{|c|}{ FLUCONAZOLE } & \multicolumn{2}{|c|}{ CLOTRIMOZOLE } & \multicolumn{2}{|c|}{ VORICONAZOLE } & \multicolumn{2}{|c|}{ ITRACONAZOLE } & \multicolumn{2}{|c|}{ KETOCONAZOLE } \\
\hline & $\mathrm{s}$ & $\mathrm{R}$ & $\mathrm{s}$ & $\mathrm{R}$ & $S$ & $\mathrm{R}$ & $S$ & $\mathrm{R}$ & $S$ & $\mathrm{R}$ & $\mathrm{S}$ & $\mathrm{R}$ & $S$ & $\mathrm{R}$ \\
\hline $\begin{array}{l}\text { C.tropicali } \\
\text { s } \\
71\end{array}$ & $\begin{array}{l}70 \\
(98.5 \%)\end{array}$ & $\begin{array}{l}1(1.5 \\
\%)\end{array}$ & $\begin{array}{l}70 \\
(98 . \\
5 \%)\end{array}$ & $\begin{array}{l}1(1 \\
.5 \\
\%)\end{array}$ & $\begin{array}{l}65(91 . \\
5 \%)\end{array}$ & $\begin{array}{l}6(9.5 \\
\%)\end{array}$ & $\begin{array}{l}63(88 . \\
7)\end{array}$ & $\begin{array}{l}8(11.2 \\
\%)\end{array}$ & $\begin{array}{l}60(84 . \\
5 \%)\end{array}$ & $\begin{array}{l}11(15 . \\
4 \%)\end{array}$ & $\begin{array}{l}69(97 . \\
1 \%)\end{array}$ & $\begin{array}{l}2(2.8 \\
\%)\end{array}$ & 71 & 0 \\
\hline $\begin{array}{l}\text { C.albicans } \\
16\end{array}$ & 16 & 0 & 16 & 0 & $\begin{array}{l}15(93 . \\
7 \%)\end{array}$ & $\begin{array}{l}1(6.5 \\
\%)\end{array}$ & 15 & 1 & 15 & 1 & 16 & 0 & 16 & 0 \\
\hline $\begin{array}{l}\text { C.dublinie } \\
\text { nsis3 }\end{array}$ & 3 & 0 & 3 & 0 & 3 & 0 & 3 & 0 & 2 & 1 & 2 & 1 & 3 & 0 \\
\hline C.famata3 & 3 & 0 & 3 & 0 & 3 & 0 & $\begin{array}{l}2(66.4 \\
\%)\end{array}$ & $\begin{array}{l}1(33.4 \\
\%)\end{array}$ & 3 & 0 & 3 & 0 & 3 & 0 \\
\hline C.kefyr3 & 3 & 0 & 3 & 0 & 3 & 0 & 3 & 0 & 3 & 0 & 3 & 0 & 3 & 0 \\
\hline C. krusei2 & 2 & 0 & 2 & 0 & 2 & 0 & )$^{1(50 \%}$ & 1 & 2 & 0 & 2 & 0 & 2 & 0 \\
\hline $\begin{array}{l}\text { C.guillierm } \\
\text { ondii2 }\end{array}$ & 2 & 0 & 2 & 0 & 2 & 0 & 2 & 0 & 2 & 0 & 2 & 0 & 2 & 0 \\
\hline Total\% & 99 & 1 & 99 & 1 & 93 & 7 & 89 & 11 & 87 & 13 & 97 & 3 & 100 & 0 \\
\hline
\end{tabular}


Yeasts are becoming important causes of morbidity and mortality in many patients, because of alternations in the immune system and invasive hospitalprocedures. ${ }^{11}$ Biofilms are a collection of microorganisms surrounded by the slime they secrete. Candida UTIs are potentially serious with a reported mortality up to $61 \% .^{12}$ The ability to form biofilms is associated with the pathogenicity and as such should be considered as an important virulence determinant during candidiasis. $^{13}$

The present study showed predominance of Non Albicans Candida compared to C. albicans. Studies by Mujikaet al., ${ }^{3}$ and Saroj et al., ${ }^{10}$ also showed an increasing prevalence of infections caused by species of Non Albicans Candida. In the present study $48 \%$ of the Candida isolates tested were found to be biofilm producers. The biofilm production of Candida species is in correlation with studies by Mohandas et al., ${ }^{2}$ andSaroj G et al., ${ }^{10}$.Biofilm production was found to occur most frequently among Non Albicans Candida species (48.0\%) than C.albicans $(25.0 \%)$. Similar findings have been reported by Saroj G et al., ${ }^{10}$ and Hetal Sida et al., ${ }^{14}$. Among the Non Albicans Candida species, the biofilm positivity occurred most frequently among isolates of $C$. tropicali $s(50.7 \%)$. C.tropicalis have also been recognized as strong slime producers by other studies by Hetal Sida et al., ${ }^{14}$. Antifungal susceptibility testing done for candida species showed sensitivity for amphotericin $\mathrm{B}$, ketoconazole, itraconazole, voriconazole, fluconazole, clotrimozole and nystatin. The antifungal sensitivity pattern was in agreement with that of Sanaa et al., ${ }^{9}$ Most of Biofilm producing Candida species were resistant to clotrimazole (11\%) and fluconazole (7\%) (Table 4). Candida biofilms may help maintain the role of fungi as commensals and pathogen, by evading host immune mechanisms, resisting antifungal treatment, and withstanding the competitive pressure from other organisms. Consequently, biofilm related infections are difficult to treat. ${ }^{15}$ Health professionals should take special care when managing urinary catheters to prevent biofilm formation, since one of the main reasons for treatment failure stems from this capacity of fungi to produce biofilms on the surface of foreign bodies. ${ }^{16}$ Hence the study emphasizes the need for an effective anti-biofilm treatment which requires improved knowledge of the pathogen itself, and also of the host response to adhesion and biofilm formation, the properties of the substrates onto which the biofilm develop and the interactions within microbial communities.

The present study suggests an increasing prevalence of Non Albicans Candida in urine samples and also shows them as strong biofilm producers compared to $C$. albicans. Biofilm formation also helps the organism to overcome host defences and is intricately linked with the ability of the organisms to adhere, colonize and exists as a persistent source of infection. Thus more remains to be determined about biofilms formed by the Non Albicans Candida as they are now frequently encountered species in candidurias.

\section{References}

1. Douglas LJ (2003). Candida biofilms and their role in infection. Trends Microbiol, 11: 30-36.

2. Mohandas V, Ballal M. Distribution of Candida Species in Different Clinical Samples and Their Virulence: Biofilm Formation, Proteinase and Phospholipase Production: A Study on Hospitalized Patients in Southern India.J Glob Infect Dis. 2011; Jan-Mar; 3(1): 4-8.

3. Mujika MT, Finquelievich JL, Jewtuchowicz V, Iovannitti CA. Prevalence of Candida albicans and 
Candida non-albicans in clinical samples during 1999-2001. Rev Argent Microbiol. 2004;36:107-12.

4. Seneviratne C J, Jin L, Samaranayeke LP. Biofilm lifestyle of Candida: A mini review Oral Dis. 2008; 14: 582-590.

5. Ramage G, Saville SP, Thomas DP, López-Ribot JL. Candida biofilms; an update. Eukaryot Cell. 2005;4:633-8.

6. Aparna MS, Yadav S. Biofilms: Microbes and Disease. The Braz.J. Infect. Dis.2008; 12: 526-530.

7. Larone, DH, Medically Important Fungi: a Guideto Identification. 1979. 2nd ed. Harper and Row Publisher, Hager's town. Maryland, New York,San Francisco, London.

8. Branchini ML, Pfaller MA, Rhine- chalk berg J, Frempong T, Isenberg HD. Genotype variation and slime production among blood and catheter isolates of $\mathrm{C}$ Parapsilosis. J Clin Microbiol. 1994;32:452-6.

9. Sanaa MA, Zeinab MK, Soheir SM,Manar RA, Sanaa SZ. Relationship between virulence factors of Candida species with candiduria and myeloperoxidase concentrations. Int.J.Curr.Microbiol. App.Sci (2015) 4(1): 108-123.

10. Saroj Golia, Vivek Hittinahalli, Sangeetha K. T, Vasudha C. L. Study of biofilm formation as a virulence marker in candida species isolated from various clinical specimens. Journal of Evolution of Medical and Dental Sciences/Volume 1/Issue 6/December-2012

11. White, T.C., Marr, K.A., Bowden, R.A.1998. Clinical, cellular, andmolecular factors that contribute to antifungal drug resistance. Clin.Microbiol. Rev., 11: 382 402.

12. Agrawal, S., Brown, C.T., Miller, S.,Grundy, C., Kulkarni, R.Upper urinary tract fungal infections. J.C.U. 3: 18189.

13. Muni S, Menon S, Chande C, Gohil A, Chowdhary A, Joshi A. Candida biofilm. Bombay Hosp J. 2012; Vol. 54, No. 1.

14. Hetal Sida, Parul Shah, Jayshri Pethani, Lata Patel, Hiral Shah.Study of biofilm formation as a virulence marker in Candida species isolated from various clinical specimens. Int J Med Sci Public Health. 2016; 5(5): 842-846

15. Baillie GS, Douglas LJ. Candida biofilm and their susceptibility to antifungal agents. Methods Enzymol.1999; 310:64456.

16. Kuhn, D.M., Chandra, J., Mukherjee, P.K.,Ghnnoum, M.A. 2002. Comparison of biofilms formed by Candida albicans and Candida parapsilosis on bio prosthetic surfaces. Infect.Immun., 70: 342 347.

\section{How to cite this article:}

Padmaja Yarlagadda, Uma Penmetcha, Naseema Shaik and Ramesh Babu Myneni. 2017. Study of Biofilm Formation \& Drug Resistance Pattern in Various Candida Species Isolated from Patients with Urinary Tract Infection. Int.J.Curr.Microbiol.App.Sci. 6(9): 3423-3430. doi: https://doi.org/10.20546/ijcmas.2017.609.420 